\title{
A SALINIDADE DO SOLO EM CANTEIROS DE ESTUFA
}

C. M. Franco

Engenheiro agrônomo, Seção de Fisiologia e Alimentação das Plantas, Instituto Agronômico de Campinas

\section{1-INTRODUÇÃO}

A fim de que as raízes das plantas possam absorver água do solo, é necessário que a pressão osmótica do suco celular seja mais elevada que a da solução do solo. Elevando-se a pressão osmótica do solo pela adiçấo de sais, a diferença existente entre a pressão osmótica das células das raízes e a da solução do solo diminui e, em consequência, diminui também a razão de absorção da água, ou melhor, se torna mais difícil a sua absorção pelas raízes. Continuando-se a elevar a pressão osmótica do solo, um ponto será atingido em que a quantidade de água que a planta absorve não é suficiente para repor a que transpira, e a planta se ressentirá, mesmo quando possa ser abundante a água no solo.

$\mathrm{Na}$ maioria dos solos, a pressão osmótica normalmente não atinge valores que dificultem a absorção da água pelas plantas. $\mathrm{O}$ fato, porém, de tal não acontecer, na maioria dos solos, não justifica, em nossa opinião, que não se considere a pressão osmótica da solução do solo como um dos fatôres que determinam a retenção da água por êle, como afirmam alguns autores (8). Há casos, como veremos adiante, em que se deve, principalmente ao elevado valor osmótico, a retenção da água pelo solo. As plantas se acomodam à elevação da pressão osmótica do solo pela concomitante elevação da pressão osmótica do suco celular de suas raízes. Essa capacidade de acomodação é, porém, limitada e varia com as espécies. E bem conhecido o caso de certos solos que se tornaram estéreis por se ter elevado demasiadamente o seu teor em sais com o emprêgo de água de irrigação bastante salina e pouco abundante. Magistad e Christiansen (7) calcularam que cêrca de 80.000 alqueires de terras irrigadas foram abandonados, nos Estados Unidos, principalmente em virtude da sua elevada salinidade.

\section{2-CAUUSAS DA SALINIDADE DOS CANTEIROS DE ESTUFA}

Em canteiros de estufa, a salinidade traz, por vêzes, transtornos aos experimentadores, viveiristas ou floricultores, dificultando o normal desenvolvimento das plantas. Não se estando prevenido, perde-se tempo à procura de outras causas, para explicar essa falta de desenvolvimento.

Os canteiros de estufa se tornam, às vêzes, salinos por uma ou algumas das seguintes razões: 
a) São frequentemente adubados em excesso, por adubações amiúde repetidas ;

b) Teor elevado em sais, da água utilizada nas regas ;

c) As regas não são feitas com suficiente abundância de água, para que se dê a lavagem do solo.

Se as regas não forem suficientemente abundantes para que haja certa lavagem do solo, mesmo que a água utilizada seja de baixo teor em sais, êstes poderão acumular-se com o tempo. Assim, por exemplo, uma água contendo cêrca de 50 miligramas de sais por litro, como a utilizada nas regas das estufas do Instituto Agronômico, é de baixo teor salino. Se utilizada, porém, na proporção de um litro por metro quadrado por dia, o que é pouco, acrescenta ao solo 18,25 gramas de sais por ano, por metro quadrado. Após vários anos, a sua contribuição para o aumento de salinidade do solo poderá ser apreciável. Como os canteiros de estufa não são, no geral, atingidos pelas águas das chuvas, êsse fator se torna de maior importância. Acresce ainda que, não sendo intenso o seu cultivo, a retirada de sais pelas plantas é pequena, o que agrava o problema.

\section{3-FALTA DE DESENVOLVIMENTO DAS PLANTAS EM UMA DAS ESTUFAS DO INSTITUTO AGRONÔMICO}

Levou-nos à elaboração do presente trabälho um fato ocorrido nos canteiros da estufa da Secção de Introdução de Plantas, do Instituto Agronômico. Essa estufa tem apenas o telhado de vidro, sendo lateralmente protegida com tela de arame de malha bem fina.

Construida em princípio de 1937, por algum tempo as sementes semeadas em seus canteiros germinavam bem e as plantas cresciam normalmente. Nos últimos anos, porém, notou-se que as plantas começaram a mostrar um desenvolvimento menor, no centro dos canteiros. Isto se foi agravando, progressivamente, até que, por fim, raras eram as espécies que conseguian germinar e crescer um pouco. Esse crescimento, que não era normal, ocorria quase que sòmente nas margens dos canteiros (est. 1-A). As plantas da margem externa dos canteiros cresciam ainda melhor do que as da margem interna. Nenhum microrganismo foi encontrado atacando as plantas. Certos fatos, tais como o murchamento das plantas, quando o solo aparentemente continha ainda umidade suficiente para o seu desenvolvimento normal, e o exíguo crescimento das raízes, que apresentavam as extremidades mortas, levaram-nos a investigar a origem dos distúrbios na salinidade do solo. Fatos semelhantes a êste foram já relatados por Davidson (2) e Conner (1).

\section{4-PRESSÃO OSMÓTICA DA SOLUÇÃO DO SOLO}

Inicialmente, com o objetivo de ver se havia alguma correlação entre o desenvolvimento das plantas nos canteiros e a pressão osmótica da solução do solo, tiramos amostras dêste na margem interna, no centro e na margem 
externa de um dos canteiros. Essas amostras foram sêcas a $105 .^{\circ} \mathrm{C}$, misturadas com água distilada na razão de 1:1, agitadas e deixadas de um dia para outro. Os valores da pressão osmótica no filtrado dessas misturas são os apresentados no quadro 1. Para a determinação da pressão osmótica empregamos o método crioscópico (9), já por nós descrito com pormenores em outro trabalho (3).

QUADRo 1.--Pressão osmótica e desenvolvimento das plantas no canteiro.

\begin{tabular}{l|c|c}
\hline \multicolumn{1}{c|}{ Local } & Pressão osmótica & Desenvolvimento das plantas \\
\hline & atmosferas & \\
Margem interna & $\mathbf{3 , 2 5}$ & regular \\
Centro & $\mathbf{6 , 7 5}$ & péssimo \\
Margem externa & 0,72 & quase bom \\
\hline
\end{tabular}

Pelo exame do quadro 1 vemos, pois, que existe correlação entre a elevada pressão osmótica da solução do solo e.a falta de desenvolvimento das plantas no canteiro, o que mostra ser o excesso de sais no solo o que prejudicava o crescimento das plantas. A pressão osmótica de 6,75 at., encontrada no centro do canteiro, é muito elevada, considerando-se que foi determinada no filtrado de uma mistura de solo e água na proporção de 1:1.

Para conclusర̃es mais seguras, procuramos efetuar o estudo das pressões osmóticas do solo com diferentes teores de umidade. Do centro dos canteiros, onde o desenvolvimento das plantas era mais prejudicado, tiramos diversas amostras superficiais, até $5 \mathrm{~cm}$ de profundidade. Essas amostras foram sêcas a $105^{\circ} \mathrm{C}$ e tratadas, como no caso precedente, para se obter o filtrado de uma mistura de solo e água na proporção de 1:1. Em uma parte do filtrado determinamos a pressão osmótica, que nos deu o valor dessa pressão na solução do solo, quando êste continha $50 \%$ de umidade. $O$ restante do filtrado, dividimo-lo em quatro porções, que foram evaporadas a $1 / 2,1 / 3$, $1 / 5$ e $1 / 7$ do volume inicial. A determinação da pressão osmótica nas frações assim obtidas nos forneceu o valor osmótico da solução do solo, quando êste continha, respectivamente, $25 \%, 16,5 \%, 10 \%$ e $7,1 \%$ de umidade.

A figura 1 reproduz os resultados obtidos. O "wilting point" do solo dos canteiros é 16,4 e vemos que, com êste teor em água, a pressão osmótica se eleva a 13,5 atmosferas.

Considerando que a pressão osmótica da solução dos solos cultiváveis (mesmo quando no "wilting point") não ultrapassa geralmente 2 atmosferas (6), e que solos com 10 atmosferas de pressão osmótica já não se prestam para cultura, vemos que, à elevada pressão osmótica dos solos dos canteiros da estufa, devemos, de fato, atribuir a falta de desenvolvimento das espécies nêles plantadas. 


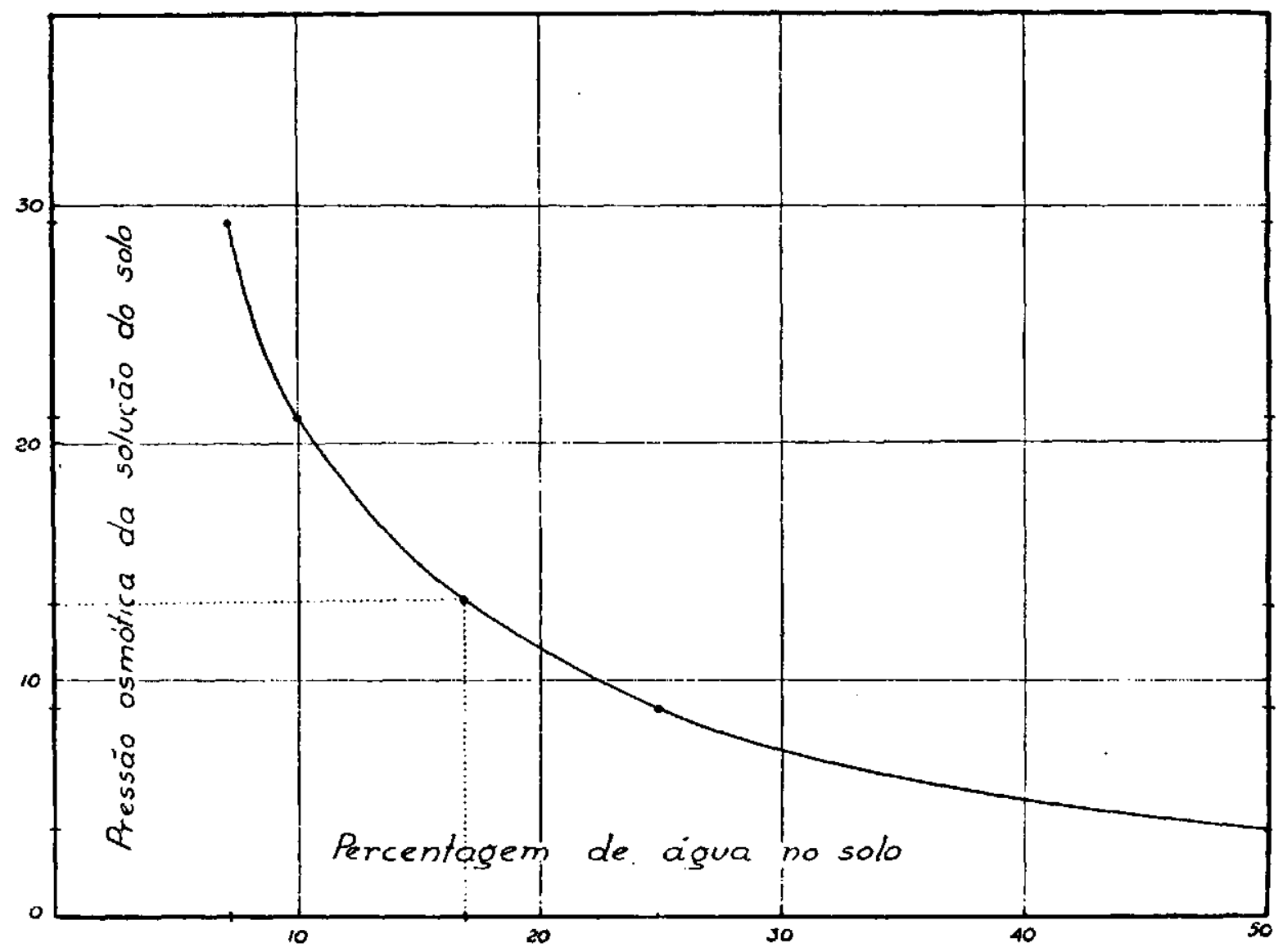

Figura 1.-Variaçăo da pressão osmótica do solo com o seu teor em água.

$\mathrm{O}$ teor médio em água encontrado antes das regas diárias, no solo daqueles canteiros, foi de $20 \%$. Vemos, na figura 1 , que, com essa umidade, a pressão osmótica já se eleva a 11,3 atmosferas, a qual, sem dúvida, é altamente prejudicial.

Ao se iniciar o presente estudo foram plantadas para observação, em um dos canteiros da estufa, várias linhas de diversas plantas, no sentido transversal. E o que vemos na estampa 1- $A$ : o milho resistiu melhor à salinidade, do que a soja e os outros feijões, pois, enquanto aquêle, embora muito mal, crescia em tôda a largura do canteiro, estas últimas espécies nem mesmo germinaram, a não ser nas margens. O melhor desenvolvimento, aí, pode ser explicado por diversos fatôres. Sendo os canteiros desprovidos de fundo pavimentado, a difusão dos sais para os lados, no solo, deve ser mais ativa nas margens, baixando portanto aí a concentração salina. Outro fator seriam os bordos de alvenaria, com cêrca de $10 \mathrm{~cm}$ de altura, os quais projetam sombra sôbre as margens dos canteiros, durante parte do dia, de manhã de um lado e à tarde do outro, diminuindo, portanto, a evaporação do solo, nas margens, e fazendo, assim, com que a concentração de sais aí não atinja valores tão elevados. Além disso, sendo de tela as paredes laterais da estufa, aquêles bordos de alvenaria protegem também as margens dos canteiros contra a ação do vento, o que ainda concorre para a diminuição da evaporação nas suas proximidades. 

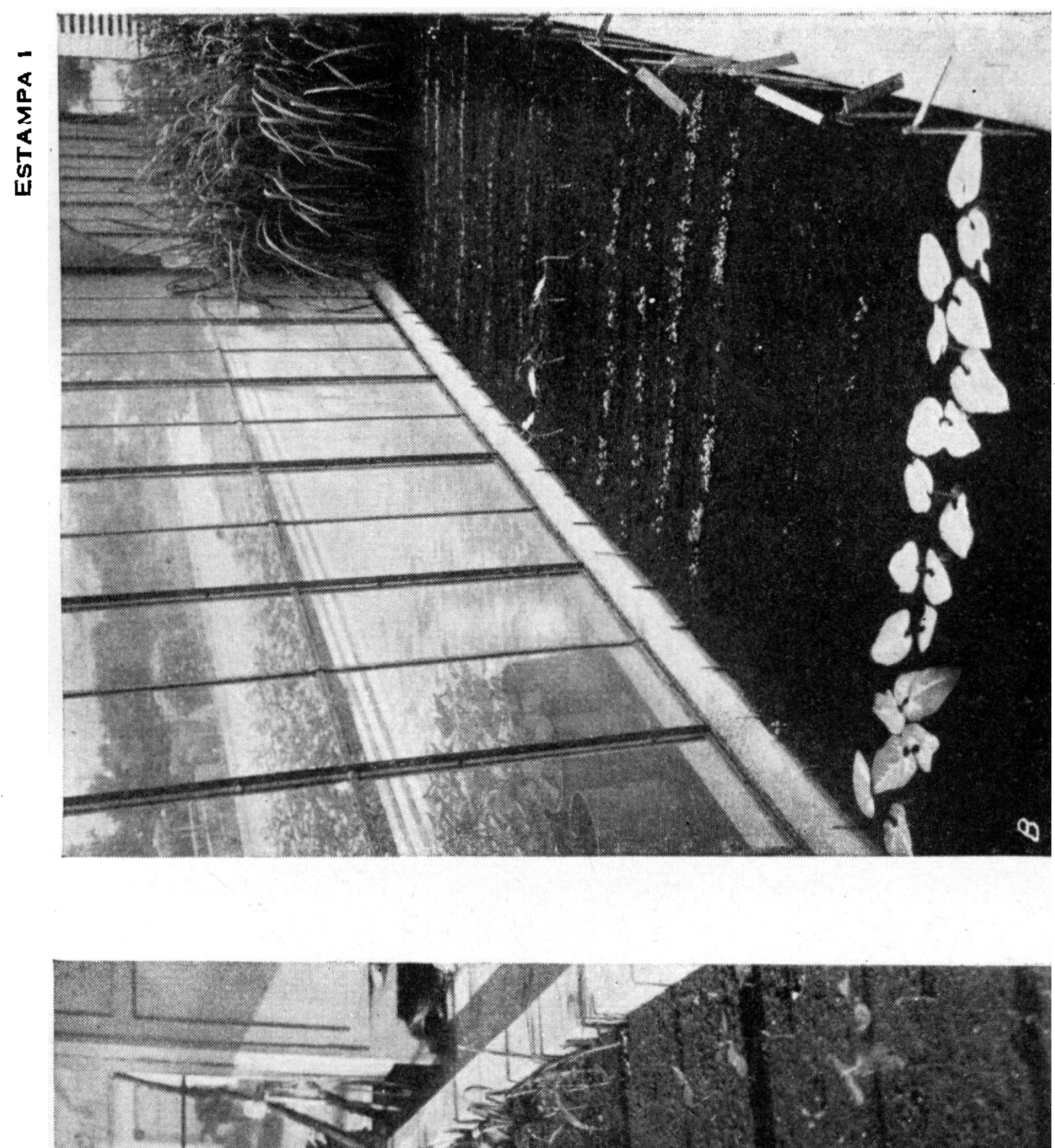

윰옴

ฉ

幽

刃ु

总

悉

占

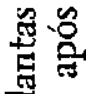

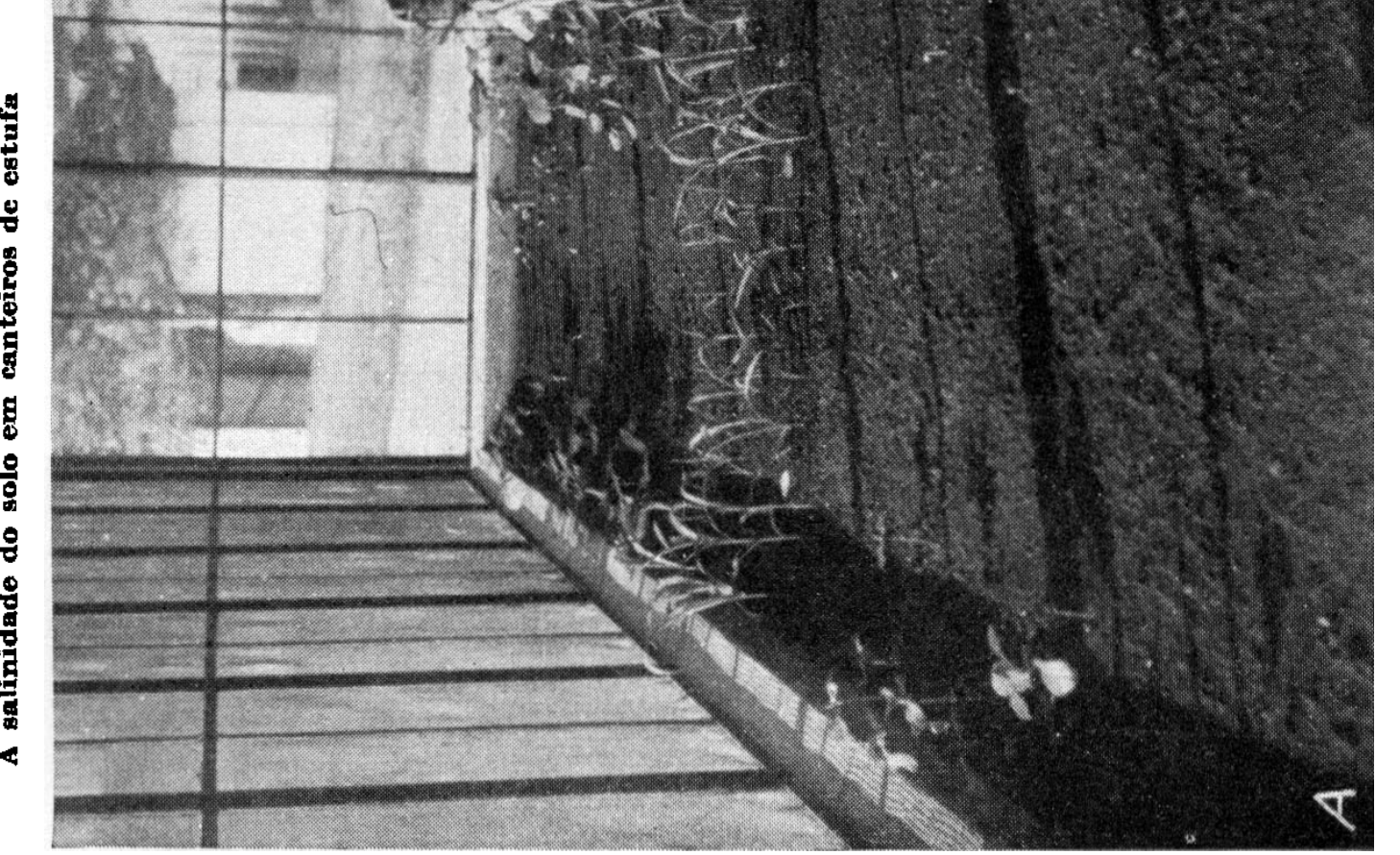

䓀

올

E

寄

岛

是

焉

1 


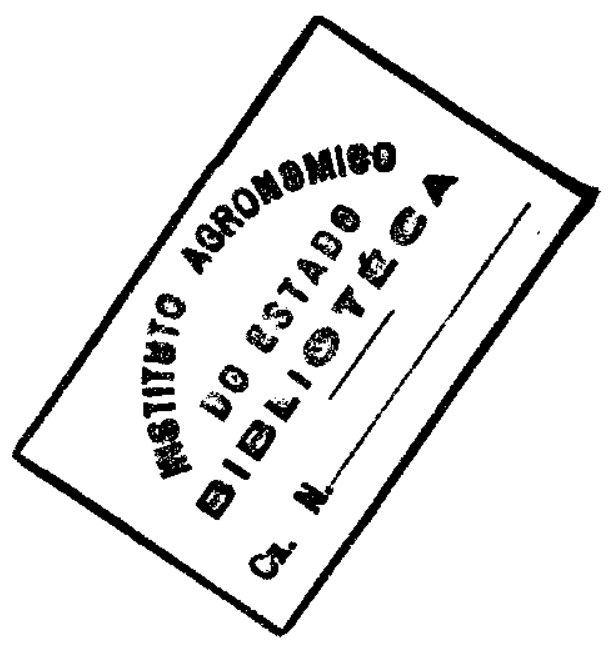




\section{5-TRATAMENTO DOS CANTEIROS, PARA SEREM U'TILIZADOS DE NOVO}

Em virtude de serem os canteiros desprovidos de fundo pavimentado, o solo pôde ser lavado por meio de abundantes irrigaçóes.

Os canteiros foram inundados até ficar o solo coberto com $3-5 \mathrm{~cm}$ de água, que, depois de algum tempo, se infiltrava tôda no solo. Isto se repetiu por 10 a 12 vêzes, tendo sido, assim, arrastado todo o excesso de sais solúveis para as camadas profundas do subsolo. Após êste tratamento, fizemos novas determinações de pressão osmótica, as quais nos deram os resultados abaixo :

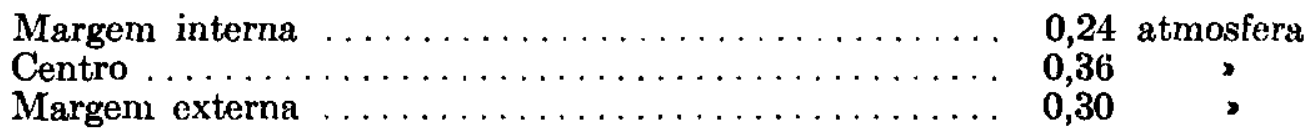

Por aí se vê que a pressão osmótica baixou consideràvelmente, passando para valores semelhantes aos encontrados em solos cultiváveis e normais.

Várias espécies vegetais foram de novo semeadas, tendo germinado bem e desenvolvido uniformemente em tôdas as regióes dos canteiros. $O$ aspecto um tanto clorótico das plantinhas, fato aliás que era de se esperar, mostrava que a lavagem do solo havia sido demasiada.

Como os canteiros estavam baixos e necessitavam de mais terra, ao invés de adubação, foi adicionada terra trazida de fora, de mistura com terriço. A seguir foram revolvidos os canteiros várias vêzes, a fim de misturar o solo lavado ao novo. Após essa operação, sementes de várias espécies foram plantadas, tendo tôdas elas germinado bem, mostrando as plantas um desenvolvimento perfeitamente normal (est. 1-B).

\section{6-A SALINIDADE E A ĀGUA INATIVA}

A água inativa ou "wilting point" do solo aumenta com a salinidade, enquanto a umidade equivalente não é influenciada, significantemente, por ela. Daí não se poder aplicar, em solos salinos, o método da determinação indireta do "wilting point", baseado na umidade equivalente. Assim é, por exemplo, que, no solo salino dos canteiros de que tratamos atrás, o "wilting point", calculado como sendo w. p. $=0,68$ U. Eq. (8), deu o valor 13,7 , ao passo que, determinado diretamente (4), o valor encontrado foi de 16,4 . Há, pois, uma diferença significante entre o "wilting point" real e o encontrado pelo cálculo a partir da umidade equivalente.

\section{SUMMARY}

It has been noticed in the greenhouse of the "Instituto Agronômico de Campinas" that many species of plants developed poorly when planted in sced beds that have been repeatedly used without change of soil.

In many cases even the seeds would not germinate in such seed beds. Experiments have showed that the lack of normal plant development in these beds is the result of the 
increase in soil salinity. This salinity may be due to additions of fertilizers or to salts introduced in the ordinary applications of water. It was found that the soil solution had an osmotic pressure of 13.5 athmospheres at the wilting point.

The tests showed that common bean (Phaseolus vulgaris $L$.) plants were more susceptible to the soil salinity than were the soybean and the corn plants.

Floading of those seed beds several times resulted in the leaching of salts and the restoring of conditions favorable for normal plant growth.

\section{LITERATURA CITADA}

1. Conner, S. D. e C. T. Gregory. Excess soluble salts as the cause of vegetable diseases in greenhouses. Proc. Ind. Acad. Sci. 37 : 385-390. 1927.

2. Davidson, $\mathbf{O}$. W. Why salts in old greenhouse soils may stunt crops. Florists Exchange and Horticultural Trade World $104: 13-14.1945$.

3. Franco, C. M. e O. Bacchi. Investigações sôbre a Tristeza dos Citrus. Bragantia 4: :541-551. 1944.

4. Franco, C. M. e H. C. Mendes. Água inativa de alguns tipos de solos do Estado de São Paulo. Bragantia 7 : 129-132. 1947.

5. Kramer, P. J. Absorption of water by plants. Bot. Rev. 11 : 310-355. 1945.

6. Magistad, O. C. Plant growth relations on saline and alkali soils. Bot. Rev. 11 : 181-230. 1945.

7. Magistad, O. C. e J. E. Christiansen. Saline soils, their nature and management. Cir. U.S. Dept. Agric. $707: 1-32.1944$.

8. Paiva Neto, J. E. e W. De Jorge. Estudo preliminar do sistema água-solo-planta no Estado de São Paulo. Bragantia 7 : 133-150. 1947.

9. Von Heirich, W. Die Kryoskopische Bestimung des Osmotischen Wertes bei Pflanzen. Abderhalden, Hand. Biol. Arbeitsmethoden 11 : 353-371. 1939. 